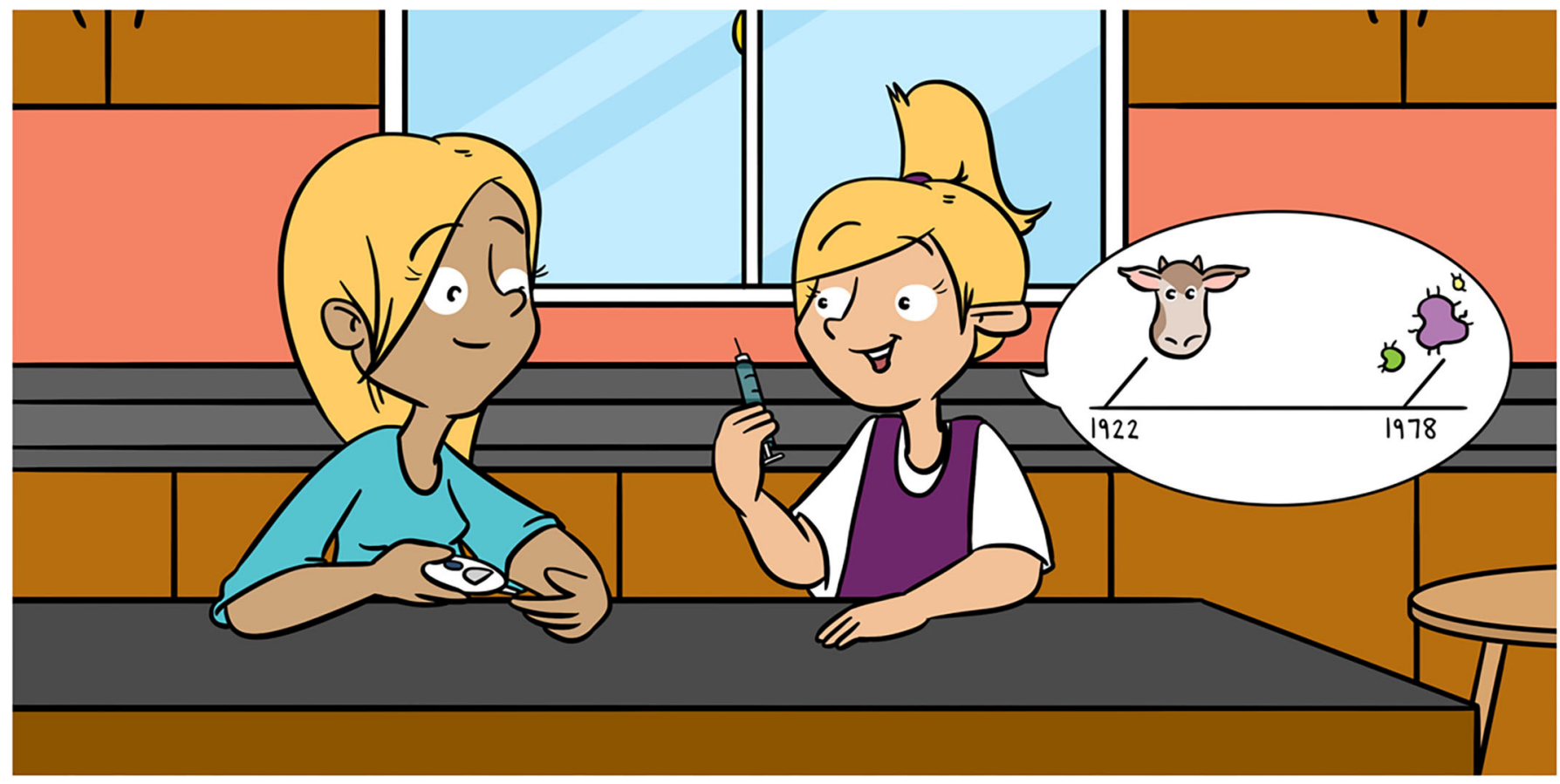

\title{
SUGAR, DOGS, COWS, AND INSULIN-THE STORY OF HOW DIABETES STOPPED BEING DEADLY
}

\section{Astrid Christine Hauge-Evans *}

Health Sciences Research Centre, Department of Life Sciences, University of Roehampton, London, United Kingdom

YOUNG REVIEWERS:

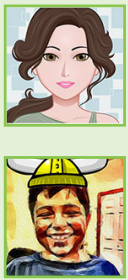

AMELIE

AGE: 12

SANTIAGO

AGE: 12
Before the discovery of insulin, diabetes was a life-threatening and untreatable illness. It was caused by very high blood sugar levels and many children died from it. In 1922, two scientists, Frederick Banting and Charles Best, treated a boy suffering from diabetes with special extracts from a cow's pancreas. The pancreas is an organ found near the stomach. The treatment lowered the boy's blood sugar to normal levels due to a chemical substance from the pancreas. This substance was later named insulin. In this article you will read about diabetes and insulin. You will see that the final discovery of insulin built on the work of many scientists before Banting and Best. It is a great story showing how the skills and determination of different people together led to a ground-breaking discovery. In 1978, human insulin was made artificially from bacteria and today it continues to save millions of lives. 


\section{DIABETES}

A condition in which glucose levels in the blood become dangerously high. In type 1 diabetes, insulin is not produced by the pancreas. In type 2 diabetes, the body does not respond to insulin and the pancreas does not make enough insulin.

\section{INSULIN}

A chemical substance made by cells in the islets of Langerhans. The main role of insulin is to help the body to use glucose as a source of energy.

\section{GLUCOSE}

Carbohydrate from the diet is made up of smaller units. Glucose is the most common and important of these units as it is the main source of energy fuel for the body.

\section{KETOACIDOSIS}

A condition in which the blood becomes acidic due to the production of high levels of ketone bodies. When glucose is not available, the liver makes ketone bodies from fat molecules to provide energy for the brain.

\section{WHAT IS DIABETES?}

A high level of sugar in the blood can be dangerous and is the main sign of an illness called diabetes. Before insulin was discovered, many people died from this illness. Diabetes has been known for a long time. The Egyptians wrote about it in medical scrolls more than 3,500 years ago in the Ebers Papyrus [1], and there are records of treatments for diabetes dating back to ancient India and China [2].

Aretaeus of Cappadocia, a Greek doctor in the 2nd century AD, first used the word "diabetes," which means "siphon" or "pass through." This word was chosen because people with untreated diabetes needed to urinate a lot, as if water flowed through their bodies. Other old medical writers described how the body wasted away and suggested that "waste" was lost in the urine. This fits with another sign of the illness, weight loss. Other symptoms include thirst, hunger, and tiredness.

The full medical name of diabetes is diabetes mellitus. Mellitus means "sweetened with honey" and was chosen because of the presence of sugar in the urine, which is caused by high levels of sugar in the blood. The sweetened urine attracts insects. Nowadays we can measure blood sugar levels directly, but before that was possible, diabetes was sometimes detected by testing whether or not ants were attracted to the sweetness of the urine.

The problem with diabetes is that, although there is plenty of sugar in the blood, the body cannot use it and instead eliminates it in the urine. Glucose is the most common type of sugar in the body and it is the main source of energy for the body's cells, including the brain cells. When someone has diabetes, the cells cannot get access to glucose and starve instead. To solve this problem, the body makes energy from fat instead of glucose. A side effect of this process is that the blood becomes very acidic. This is called ketoacidosis and it can cause a person to go into a coma or even die. It is therefore extremely important to help the cells use glucose and to lower blood glucose levels.

\section{DIFFERENT TYPES OF DIABETES}

There are at two main types of diabetes, type 1 and 2, and both are linked to a substance called insulin. Insulin is a chemical that is normally made by the body and it controls blood glucose levels, mainly by signaling to cells that they need to take up glucose from the blood. In type 1 diabetes, people cannot make insulin. In type 2 diabetes, insulin is at first being made, but the cells cannot respond to it properly. This is referred to as insulin resistance. In both cases, glucose is not moved into the cells. With time, people who develop type 2 diabetes also become less good at making insulin. 
Figure 1

The pancreas is located next to the stomach, liver, and small intestine. In this image the stomach is not shown, so you can see the pancreas. The duodenum, which is the top part of the small intestine, is connected to the stomach (figure modified from

Freepik.com resource).

\section{INSULIN}

\section{RESISTANCE}

A condition in which cells do not detect or respond to insulin. Insulin-resistant cells fail to take up glucose from the blood and thus cannot use glucose for their energy needs.

\section{PANCREAS}

An organ which helps the conversion of food to energy in the body by producing chemical messengers

(hormones), such as insulin. It also makes digestive enzymes, which help break down food in the small intestine.

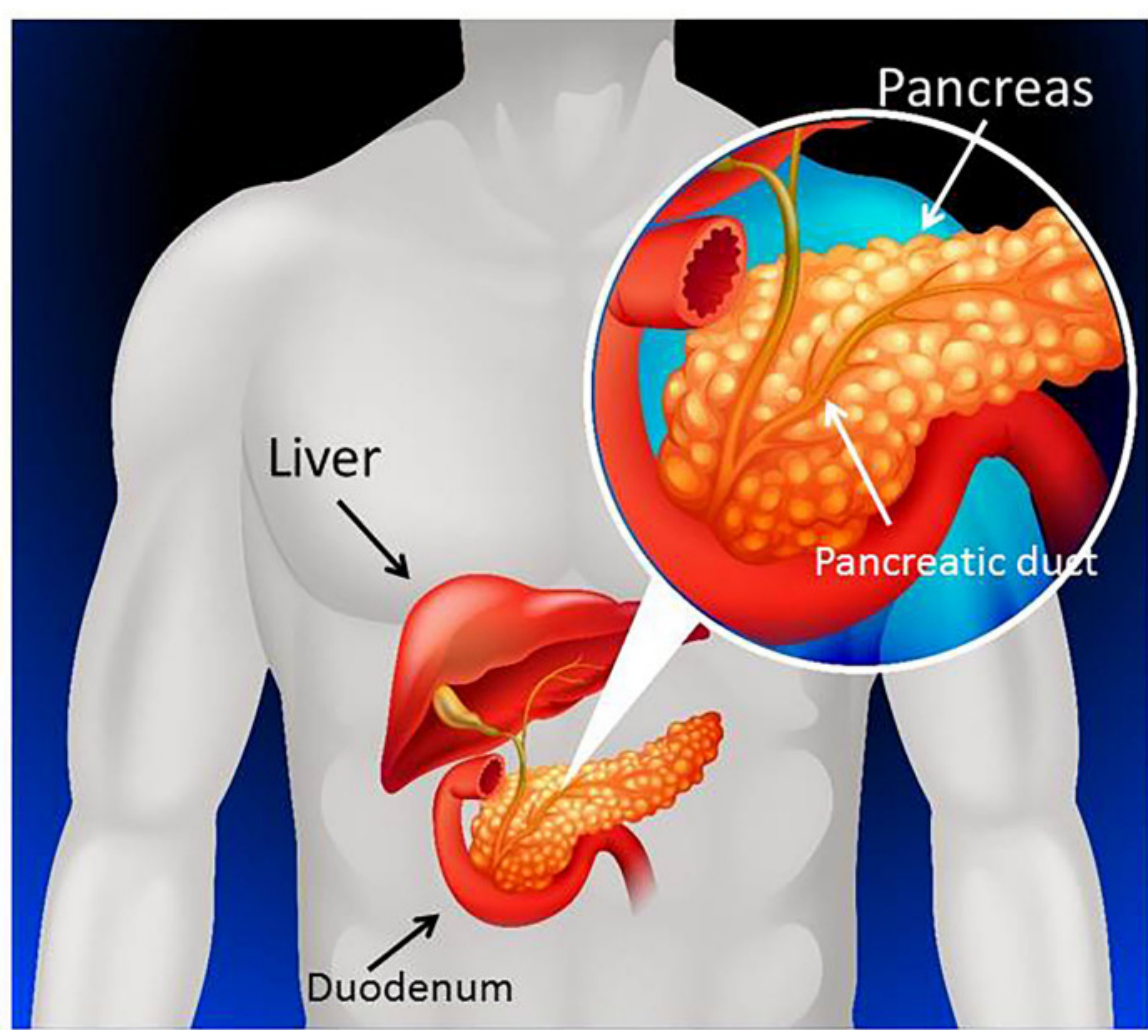

Figure 1

\section{WHAT CAUSES HIGH LEVELS OF GLUCOSE IN THE BLOOD?}

Our bodies get energy from the foods we eat. The main parts of food are fats, carbohydrates, and proteins. Carbohydrates are an essential energy source and are found in foods, such as bread, rice, and pasta but also in fruit, vegetables, and dairy products. Carbohydrates are broken down in the stomach and intestine into smaller units, including glucose. In the small intestine, glucose is transferred into the blood stream. Therefore, glucose levels in the blood increase after a meal. Normally, the blood will transport the glucose to cells all over the body, where it is taken up with the help of insulin and used as a source of energy.

Some famous experiments in 1890 by two German doctors, Oskar Minowski and Joseph von Mering, showed that an organ next to the stomach and the liver called the pancreas (Figure 1) is also essential for controlling blood glucose levels. If the pancreas was removed in dogs, the animals would very rapidly develop serious signs of diabetes [3]. 
Figure 2

The islets of

Langerhans are small clusters of cells scattered throughout the pancreas, shown here as small groups of blue dots. The square in the lower right shows a section of a real pancreas under a microscope, where you can see an islet surrounded by non-islet pancreas. Beta cells make insulin and alpha cells make another pancreatic hormone, glucagon. Insulin and glucagon are released into the blood stream via a type of blood vessel, the splenic artery (pale purple arrows). Release of digestive enzymes into the small intestine is shown with orange arrows (see glossary) (from: Wikimedia Commons: The pancreas).

\section{ISLETS OF}

\section{LANGERHANS}

Groups of cells located in the pancreas. They are responsible for the production of insulin and other hormones from the pancreas.

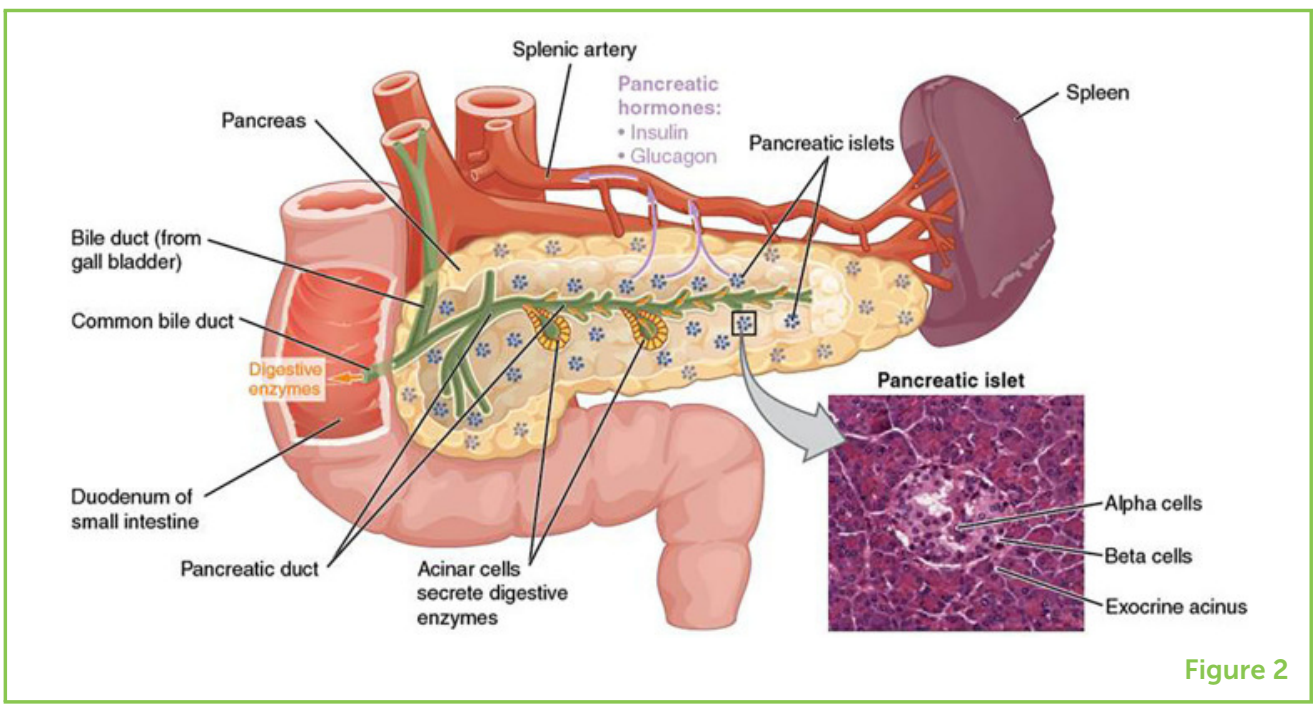

\section{WHAT IS SPECIAL ABOUT THE PANCREAS?}

In 1869, a medical student named Paul Langerhans was studying a rabbit pancreas under the microscope. He saw something interesting-not all pancreatic cells were the same. There were clusters of similar-looking cells dotted throughout the pancreas like small islands in the sea. Langerhans did not know why the cells were arranged this way or whether they were different from the rest of the pancreas. In 1893, these small mini-organs were named islets of Langerhans by another scientist, Edouard Laguesse, who saw the same pattern in the human pancreas. We now know that there are about one million of these islets in a human pancreas (Figure 2). Laguesse suggested that these islets could make a chemical that might regulate blood glucose levels, but at that time it was just an idea.

Other observations helped scientists develop this idea further. The pancreas is connected to the small intestine via a tube called the pancreatic duct. If this tube was blocked experimentally, all the non-islet cells eventually died. However, the islets kept their normal structure for much longer, which confirmed that islets really were different from the rest of the pancreas.

Scientists also noticed that urine glucose levels did not increase in animals that had their pancreatic ducts blocked, because their islets were still working. In contrast, glucose levels were high in animals that had the whole pancreas removed. These types of experiments were carried out by many different scientists from Italy, Germany, France and the UK around the turn of the 19th century [3]. They suggested that only the islets, and not the rest of the pancreas, control blood glucose. It was later discovered that the islets control blood glucose levels through the production of insulin. 


\section{INSULIN PRODUCED BY THE ISLETS OF LANGERHANS CONTROLS GLUCOSE LEVELS}

But how would it be possible to get hold of insulin to treat people with diabetes? Two scientists, with the help of their co-workers, have become famous for doing just that. Frederick Banting was from Canada and worked as a medical officer during the First World War, where he was injured. Once home again, he read about the experiments other scientists had done and decided to isolate islets from the pancreas and extract the insulin from them. He started working in the laboratories of a professor in Toronto, John MacLeod, together with a research assistant, Charles Best. They carried out experiments with dogs in which the pancreatic ducts were blocked, just as Banting had read about. Since the non-islet pancreas broke down during this treatment, they were able to isolate the islets.

Getting the insulin out of the islets was more difficult, and they had to repeat their experiments many times to get the insulin pure enough. Together with another team member, James Collip, they were eventually able to remove unwanted chemicals and concentrate the insulin from the pancreas. Banting also learned that they could use pancreas extract from cows rather than dogs. This was an important finding, because the cow pancreases were available from animals already killed for food, and much more insulin could be extracted. Excitingly, the scientists found that the purified insulin reduced blood glucose levels when it was injected into diabetic animals and then they were ready to test the extract in humans [4].

Banting and Best worked across the road from a hospital where a 14-year-old boy named Leonard Thompson was a patient, suffering from diabetes. On 11th January 1922, Thompson was injected with the insulin made by Collip, Best, and Banting, but unfortunately it did not work. Collip then made an even purer extract, which was used on 23 January 1922-this time it worked! Leonard's blood glucose levels went down, his blood became less acidic, and he felt a lot better [5]. The same happened when six other people on the ward received the treatment.

This was the turning point-it meant that diabetes was no longer deadly. But there was still work to do. Large amounts of insulin were needed, so scientists developed methods of scaling up its production. They also discovered the genetic code for human insulin and set up clever experiments in which that code was inserted into bacteria that would then make large amounts of human insulin. In 1978, human insulin was made from bacteria for the first time and it continues to save millions of lives today. 


\section{ONE DISCOVERY-MANY SCIENTISTS}

Banting and MacLeod received the Nobel Prize in 1923, but the discovery of insulin was due to the work of many scientists. It started with medical observations in the ancient world and went on to involve people from countries across Europe and America. Scientists throughout the world still carry out diabetes research. Some scientists work on improving diabetes treatment and others investigate why islets stop making insulin in the first place. Some study whether certain cells can be changed to become like islets, so that they will make insulin. But the ultimate aim is to one day find a way to prevent or even cure diabetes, which will improve and save the lives of millions of people around the world.

\section{ACKNOWLEDGMENTS}

Figure 1 has been designed using a resource from Freepik.com and Figure 2 is modified from the free image depository Wikimedia Commons (File 1820: The Pancreas; OpenStax College/CC BY (https: //creativecommons.org/licenses/by/3.0).

\section{REFERENCES}

1. Loriaux, D. L. 2006. Diabetes and the Ebers Papyrus 1552 B.C. Endocrinologist 16:55-6. doi: 10.1097/01.ten.0000202534.83446.69

2. Oubre, A. Y., Carlson, T. J., King, S. R., and Reaven, G. M. 1997. From plant to patient: an ethnomedical approach to the identification of new drugs for the treatment of NIDDM. Diabetologia 40:614-7. doi: 10.1007/s001250050724

3. Vecchio, I., Tornali, C., Bragazzi, N. L., and Martini, M. 2018. The discovery of insulin: an important milestone in the history of medicine. Front. Endocrinol. 9:613. doi: $10.3389 /$ fendo.2018.00613

4. Rosenfeld, L. 2002. Insulin discovery and controversy. Clin. Chem. 48:2270-88. doi: $10.1093 /$ clinchem/48.12.2270

5. Banting, F. G., Best, C. H., Collip, J. B., Campbell, W. R., and Fletcher, A. A. 1922. Pancreatic extracts in the treatment of diabetes mellitus. Preliminary report. Can. Med. Assoc. J. 12:141-6.

SUBMITTED: 20 July 2020; ACCEPTED: 11 March 2021; PUBLISHED ONLINE: 08 April 2021.

EDITED BY: Bergithe Eikeland Oftedal, University of Bergen, Norway

CITATION: Hauge-Evans AC (2021) Sugar, Dogs, Cows, and Insulin-The Story of How Diabetes Stopped Being Deadly. Front. Young Minds 9:585489. doi: 10.3389/ frym.2021.585489

CONFLICT OF INTEREST: The author declares that the research was conducted in the absence of any commercial or financial relationships that could be construed 


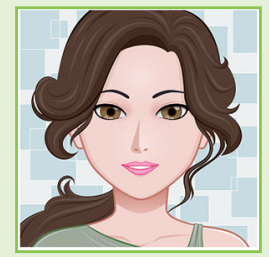

as a potential conflict of interest.

COPYRIGHT @ 2021 Hauge-Evans. This is an open-access article distributed under the terms of the Creative Commons Attribution License (CC BY). The use, distribution or reproduction in other forums is permitted, provided the original author(s) and the copyright owner(s) are credited and that the original publication in this journal is cited, in accordance with accepted academic practice. No use, distribution or reproduction is permitted which does not comply with these terms.

\section{YOUNG REVIEWERS}

\section{AMELIE, AGE: 12}

I have been participating in Frontiers for Young Minds for the past 2 years. Reviewing papers is one of my passions as well as reading, painting, drawing, and writing. Through reading these scientific papers, I have learnt a lot about health and disease. I love to travel and my favorite animal is the pangolin.

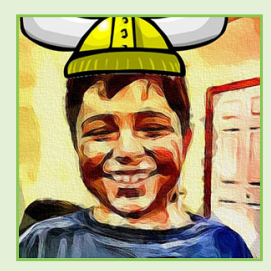

\section{SANTIAGO, AGE: 12}

Hello my name is Santiago and I am 12 years old, you can call me Santi. My favorite sport is soccer. I play for a team and my position is defending midfield. I like to play with my friends. I am in the sixth grade. I like History, Science, and especially chemistry or lab experiments.

\section{AUTHOR}

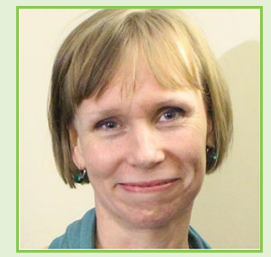

\section{ASTRID CHRISTINE HAUGE-EVANS}

I am a scientist in the Department of Life Sciences at University of Roehampton in London, UK, where I teach Nutrition and Health. I am interested in how the pancreatic islets make insulin and how this process sometimes fails in diabetes. There are many factors both inside and outside the body which affect this process. They include signals from the brain, the stomach and gut, as well as signals from cells within the islets. I am interested in how the cells in the islets talk to each other and change the production of insulin. I am also studying how other things in our diets, such as coffee and whole grains, can improve or worsen how well the islets make insulin. *Astrid.Hauge-Evans@roehampton.ac.uk 